\title{
Application of activators for hydrogen peroxide bleaching at low temperature
}

\author{
Gang Huang ${ }^{a}$, Junhua Wang ${ }^{b}$, Fengchun Dong ${ }^{c}$ and Yongtang $\mathrm{Jia}^{\mathrm{d}}$ \\ College of Textile and Clothing, Wuyi University, Guangdong, P.R.China, 529020 \\ ahg@wyu.cn, bwjh@wyu.cn, Dongfengchun@wyu.cn, dyongtjh@163.com
}

Keywords: TAED, OBA, Hydrogen Peroxide, Bleaching

\begin{abstract}
The effects of two activators for activating $\mathrm{H}_{2} \mathrm{O}_{2}$ bleaching at low temperature were studied in this paper. The results show that: (1) both 1,2-bis-(diacetamido)-ethane (TAED) and sodium 4-(2-decanoyloxyethoxycarbonyloxy) benzenenesulfonate (OBA) can catalyze the $\mathrm{H}_{2} \mathrm{O}_{2}$ bleaching at low temperature, e.g. $70{ }^{\circ} \mathrm{C}$. The whiteness of cotton bleached with the two activators was comparable to those bleached without catalysts at high temperature (e.g. $90{ }^{\circ} \mathrm{C}$ ), while the tensile strength increased by 10\%; (2) the data of whiteness and tensile strength of cotton fabric bleached with TAED were higher than those bleached with OBA; (3) the optimum conditions of cotton fabric treated by TAED were: TAED: $\mathrm{H}_{2} \mathrm{O}_{2}=1: 6$ (mass ratio), $70{ }^{\circ} \mathrm{C}, 30 \mathrm{~min}$.
\end{abstract}

\section{Introduction}

Hydrogen peroxide is the most popular oxidant to remove natural colorants of cotton fibers. Traditionally, the oxygen bleaching is conducted at high temperature $\left(95^{\circ} \mathrm{C}\right)$, which causes damage to the fibers and needs high energy costs [1-3]. Thus low-temperature oxygen bleaching becomes one of the key technologies in dyeing field. The addition of activator is an effective way to reduce the temperature of oxygen bleach [4-7]. Among the activators, 1,2-bis-(diacetamido)-ethane (TAED) and 4-(2-decanoyloxyethoxycarbonyloxy) benzenenesulfonate (OBA) (Fig. 1) are the most widely used [8]. To obtain the optimum conditions of the two activators, the effect of temperature, the applied amount of activator and time were studied in this paper.<smiles>CC(=O)NCCCN(C(C)=O)C(C)=O</smiles>

TAED

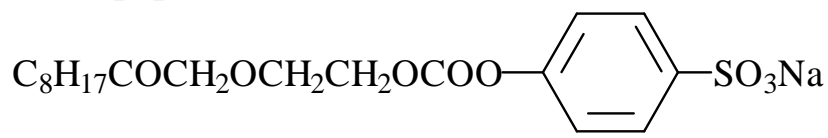

OBA

Fig. 1 the structures of TAED and OBA

\section{Experimental}

Material. Cotton weave fabric $(19.4 \times 19.4$ tex, $267.7 \times 267.7 / 10 \mathrm{~cm})$; $30 \%$ hydrogen peroxide (A.R), $\mathrm{Na}_{2} \mathrm{SiO}_{3}$ (A.R) and $\mathrm{NaOH}$ (A.R) were purchased from Guangzhou Chem. Ltm. Co. TAED and OBA were provided by Hanseatic Chemical Ltm. Co. (Zhejiang, China)

Bleaching condition. The peroxygen bleaches (with or without activator) were performed under the following condition: $\mathrm{NaOH}(2 \mathrm{~g} / \mathrm{L}), \mathrm{H}_{2} \mathrm{O}_{2}(6 \mathrm{~g} / \mathrm{L}), \mathrm{Na}_{2} \mathrm{SiO}_{3}(6 \mathrm{~g} / \mathrm{L})$ at varied temperature $(60,70$, 80 and $90{ }^{\circ} \mathrm{C}$ ), mass ratio of activator to $\mathrm{H}_{2} \mathrm{O}_{2}(1: 1,1: 2,1: 4,1: 6)$ and time (30 and $60 \mathrm{~min}$ ).

Tests. (1) Whiteness were tested with whiteness meter (WSB-V intelligent, Dacheng Photoelectric Instrument Com, Hangzhong, China) according to GB/T8424.2-2001.

(2) Tensile strength were tested with tensile strength tester (YG026PC, Ningbo Text. Mech. Com, Zhengjiang, China) according to GB/T 3923.1-1997.

\section{Result and discussion}


The effect of temperature. To investigate the effect of temperature on the whiteness and tensile strength of the treated fabric, the bleaches were carried out under the condition of TAED (or OBA): $\mathrm{H}_{2} \mathrm{O}_{2}=1: 6$ for $30 \mathrm{~min}$, the results were shown in Fig. 2.

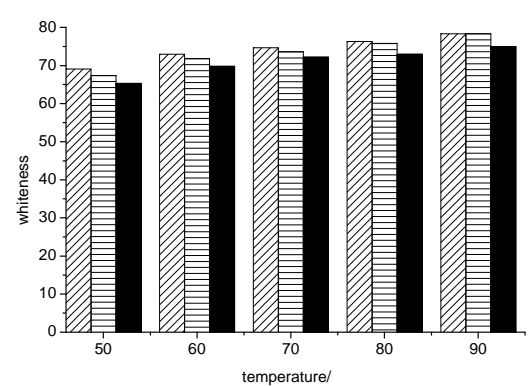

(a)

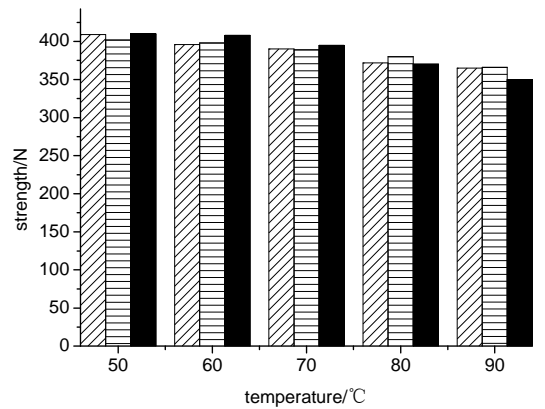

(b)

Fig. 2 Effect of temperature on whiteness, tensile strength (ZI/TAED $\rightleftarrows$ OBA without activator)

It can be seen from Fig. 2 (a), the whiteness increased with the increase of temperature. It was caused by the rapid decomposition of hydrogen peroxide at higher temperature. The bleaching effectiveness of TAED was much greater than that of OBA. With the addition of activator TAED, the whiteness of fabric treated at $70{ }^{\circ} \mathrm{C}$ was almost comparable to that of fabric treated at $90{ }^{\circ} \mathrm{C}$ with traditional method (without the addition of activator).

It can be found in Fig. 2 (b) that the fabric tensile strength also decreased with raising temperature. At $70{ }^{\circ} \mathrm{C}$, the tensile strengths of fabric treated with TAED and OBA were 390 and $389 \mathrm{~N}$, respectively. Comparing with the un-treated fabric $(416 \mathrm{~N})$, the loss of tensile strength was less than $6 \%$. When the temperature was higher than $70{ }^{\circ} \mathrm{C}$, the tensile strengths decreased quickly. At temperature of $90{ }^{\circ} \mathrm{C}$, the tensile strength of fabric treated without activator was $350 \mathrm{~N}$, i.e., the loss of tensile strength was $16 \%$, which was increased by $10 \%$ than that of fabric treated with activator at 70 ${ }^{\circ} \mathrm{C}(390 \mathrm{~N})$. Therefore, to maintain a relative high whiteness and tensile strength, the optimum temperature should be $70{ }^{\circ} \mathrm{C}$.

The effect of amount of activator. To explore the influence of amount of activator on the whiteness and tensile strength of the treated fabric, the breaches were performed under the condition of temperature $70{ }^{\circ} \mathrm{C}$ for $30 \mathrm{~min}$. The results were shown in Fig. 3

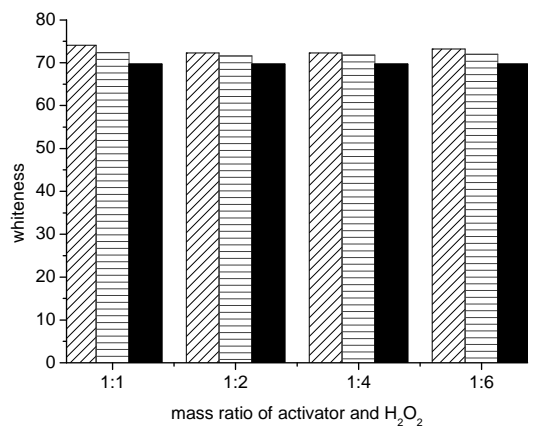

(a)

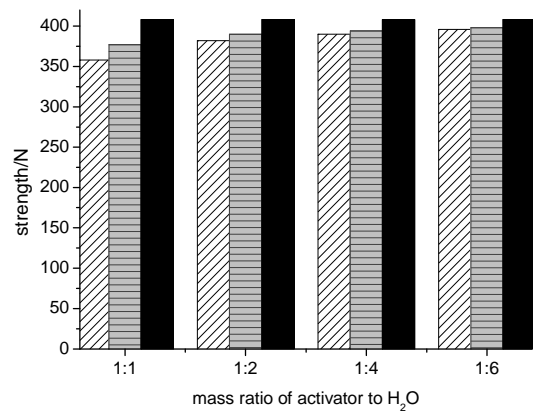

(b)

Fig. 3 Effect of amount of activator on whiteness and tensile strength $\left(70{ }^{\circ} \mathrm{C}, 30 \mathrm{~min}\right)$ ( $\mathrm{ZZT}$ TAED $\rightleftharpoons$ OBA without activator)

It can be observed from Fig. 3 (a) that the whiteness of treated fabric can be improved by the addition of both TAED and OBA, and the former was more effective than that of the latter. The efficiency of the two activators was rarely influenced by their amount applied. As shown in Fig. 3 (b), the tensile strengths of fabric treated with the two activators were lower than that of fabric treated without the addition of activators, and the influence of TAED was more pronounced than that of OBA. The tensile strength decreased with the increase of mass ratio of activator to $\mathrm{H}_{2} \mathrm{O}_{2}$. The tensile strength of bleached fabric without the addition of activator was $408 \mathrm{~N}$, closed to the un-treated fabric 
(416 N), may due to the low decomposition of $\mathrm{H}_{2} \mathrm{O}_{2}$ at this relatively low temperature $\left(70{ }^{\circ} \mathrm{C}\right)$. At this relatively low temperature, the decomposition of $\mathrm{H}_{2} \mathrm{O}_{2}$ increased greatly by the addition of activators. Although the tensile strength of fabric treated with TAED (mass ratio of TAED/ $\mathrm{H}_{2} \mathrm{O}_{2}=1: 6$ ) reduced to $396 \mathrm{~N}$, it was still higher than that of fabric treated with conventional bleaching method (350 N) as shown in Fig. 2 (b). Furthermore, its whiteness (73.2) was higher than that of fabric treated without the addition of activator (69.7). Therefore, taking both whiteness and tensile strength into account, the optimal mass ratio of TAED to $\mathrm{H}_{2} \mathrm{O}_{2}$ was 1:6.

The effect of process time. To investigate the effect of process time on whiteness and tensile strength of bleached fabric, the bleaches were conducted under the condition of 30 and 60 min, respectively, the mass ratio of TAED (or OBA): $\mathrm{H}_{2} \mathrm{O}_{2}=1: 6$ (Fig. 4).

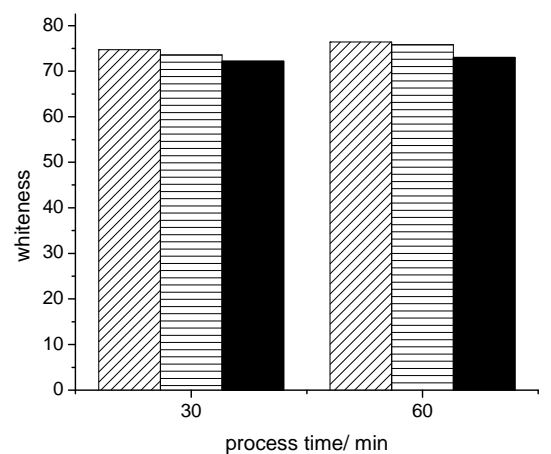

(a)

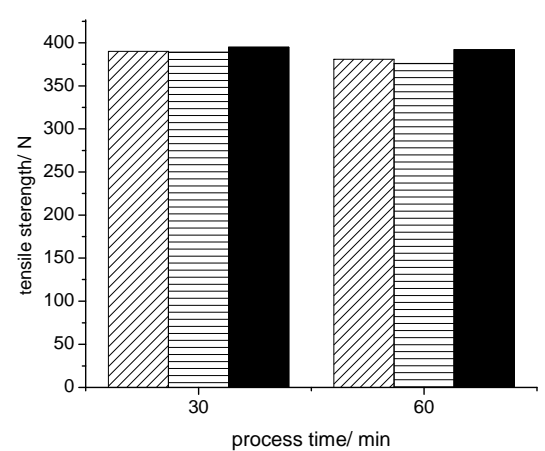

(b)

Fig. 4 Effect of process time on whiteness and tensile strength $\left(70{ }^{\circ} \mathrm{C}\right)(\mathbb{Z} \mathrm{TAED} \rightleftharpoons \mathrm{OBA}$ without activator)

It can be found from Fig. 4 (a) that the whiteness was improved by the addition of activator at both the process time of 30 and $60 \mathrm{~min}$. And the whiteness of fabric treated with TAED was higher than that with OBA. With increasing the process time from 30 to $60 \mathrm{~min}$, the whiteness of fabric treated with TAED only slightly increased, namely it took extra $30 \mathrm{~min}$ for the little increase of whiteness (from 74.7 to 76.4). In regard to the consumption of energy and time during this period, it would be more economic to treat the fabric for $30 \mathrm{~min}$. From Fig. 4 (b), it can be found that with the increase of process time, the tensile strength of treated fabric decreased. The tensile strength of bleached fabric treated with TAED $(391 \mathrm{~N})$ was higher than that with OBA (381 N) for $30 \mathrm{~min}$. Considering both the whiteness and tensile strength, the process time of 30 min was more desirable.

\section{Conclusion}

The effects of two activators (TAED and OBA) on whiteness and tensile strength of cotton fabric bleached with $\mathrm{H}_{2} \mathrm{O}_{2}$ were studied. The results show that: (1) the addition of the two activators can accelerate the decomposition of $\mathrm{H}_{2} \mathrm{O}_{2}$ at low temperature $\left(70{ }^{\circ} \mathrm{C}\right)$, resulting in a satisfactory whiteness which was comparable to that of fabric bleached with conventional method $\left(90{ }^{\circ} \mathrm{C}\right.$ and without activator). Moreover, their tensile strength loss reduced by $10 \%$. (2) the bleaching performance of TAED was more effective than that of OBA at $70{ }^{\circ} \mathrm{C}$. (3) the optimum bleaching conditions of TAED bleaching were shown as follows: the mass ratio of TAED to $\mathrm{H}_{2} \mathrm{O}_{2}$ of $1 / 6$, temperature of $70{ }^{\circ} \mathrm{C}$, and process time of $30 \mathrm{~min}$.

\section{Acknowledgements}

This work was financially supported by the Guangdong Natural Science Foundation (Project No. 10152902001000014 and No. S2011010001047).

\section{References}

[1] S. Michacl and P.G. William. Text. Chem. Color. Vol. 29 (1997), p. 12. 
[2] S.H. Zeronian, M.K. Inglesby. Cellulose. Vol. 2 (1995), p: 265.

[3] M. Hashem and M. E.Bisi, S. Sharaf and R. Refaie. Carbohyd. Polym. Vol. 79 (2009), p. 533.

[4] O.E. Ismal, A.T. Ozguney and A. Arabau. AATCC Rev. Vol. 7 (2007) p. 34.

[5] W.S. Hickman. Rev. Prog. Color. Vol. 32 (2002) p. 13.

[6] J.J. Lee, D. Hinks, S.H. Lim and P. Hauser. Cellulose. Vol. 17 (2010), p. 671.

[7] S.H. Lim, J.J. Lee, D.Hinks and P. Hauser. Color. Technol. Vol. 121 (2005), p. 89.

[8] P.K. Lavric, F. Kovac, P.F. Tavcer, P. Hauser and D. Hinks. Color. Technol. Vol. 123 (2007), p. 230. 